\title{
The Influence of Antenna Radiation Pattern to the Link Performance between LEO Terminals and Relay Satellite
}

\author{
Qu Xiaoyun, Yang Zhiqun, and Li Xiangyang
}

\begin{abstract}
The Relay Satellite acts as the bridge between the user spacecrafts and the ground stations. The link performance between the relay satellites-Tianlian-1 and LEO terminals is analyzed using STK software in this paper. For small user terminal system, the link performance of the user spacecraft to the relay satellite has great relation to characteristic of the antenna pattern except for the orbit of the user spacecraft. Taking the satellite at height of $500 \mathrm{~km}$ earth orbit for consideration, the access simulation are performed at different orbit inclination and different antenna pattern types of the user spacecrafts. From the simulation result, the relationship among the antenna pattern, the orbit inclination and the total access duration is shown intuitively, the access region and the access times are also shown directly at the same time. The simulation results are helpful for the system design for lower power cost and longer access time.
\end{abstract}

Index Terms-Relay satellite, tianlian-1, LEO, simulation, antenna pattern, $\mathrm{STK}$.

\section{INTRODUCTION}

The TDRSS (Data Relay Satellite System) is a system which can supply the data relay and TT\&C (Telemetry Tracking and Command) service for the target aircraft with low earth orbit [1]. TDRSS include three parts: the part in the space (relay satellite), the user spacecraft, and the part on the earth. With more request of longer access time, real time TT\&C and multi-spacecraft TT\&C, etc, TDRSS get fast development in the recent twenty years.

At present, USA and Russian are all have the relatively independent TDRSS themselves. USA took the lead on studying and building the first TDRSS, after 7 relay satellites had been sent from April of 1983 to July of 1995, the coverage of the spacecraft of LEOIMEO has reach to $85 \%$, which can offer service on TT\&C for carrier rocket, missile, long distance remote sensing plane, flat roof on the sea etc, at the same time. After sending the relay satellite in 2001, the European space agency has done a great deal of experiment; Japan is studding the own relay satellite actively; China set up the first generation DRSS(Data Relay Satellite System) successfully after the third relay satellite was sent in 2012 .

With the spread of the application of the relay satellite, the study on small user terminal system has got rapidly development. The user terminal system of USA has developed from the first generation to the fourth generation, the light and small ones get rapidly progress especially. The

Manuscript received March10, 2015; revised November 17, 2015.

The authors are with Shandong Aerospace Electro-Technology Institute, Yantai, China (e-mail: selina.qu@163.com, yyangzq@163.com, lixy513@163.com). access of the user spacecraft to the relay satellite has great relation to characteristic of the antenna pattern except for the characteristic of the orbit of the user spacecraft, especially for the fixed antenna pattern. The compatible antenna pattern can realize longer time access at the same power cost.

The link performance between the relay satellites-Tianlian-1 and LEO terminals is analyzed using STK software in this paper. The analysis is mainly focus on different orbit inclination and different antenna pattern types of the user spacecrafts.

Tianlian-1 includes three relay satellites which were sent by China.

\section{ACCESS ANALYSIS}

Access coverage is the common work in the application of communication system. The analysis result of access coverage is used for the revise of the communication link [2]. STK is a kind of modern analysis and visible simulation software used in space industry, it can analysis the complex task on the earth, in the sea, in the sky and in the space quickly, and offer the analysis result in graph and text style which is prone to be understand [3], [4].

The original setup of the analysis is as following:

Create the orbit and altitude of the relay satellite and the terminal, the height of the orbit of the terminal spacecrafts is set as $500 \mathrm{~km}$, and the orbit type is sun synchronous;

The antenna type of the terminal sensor is fixed beam antenna, the sensor of the terminal is located on the side which is opposite to the earth;

The axial direction of the terminal antenna is the $0^{0}$ elevation angle, which is vertical to the plane of the orbit of the terminal spacecraft;

Set the start and stop time for the terminal spacecraft according to the task, in the simulation in this paper, which is set as one day.

\section{A. Pattern of Terminal Antenna}

From the result of the communication chain budget, for limited power cost small terminal of relay satellite can access to the relay satellite when the gain of fixed terminal antenna is bigger than $2 \mathrm{dBi}$. The beam type of the fixed small antenna could be simple conical, complex conical, loop etc.

For the loop type beam, like the pattern of symmetry dipole, the elevation angle of the antenna is lower, so when the antenna is mounted on the carrier the visual field will be shelter from the equipment on the carrier. Considering the actualization environment for the engineering project, the simple and shaped complex conical pattern will be analyzed in this paper for the access analysis between the terminal 
antenna and the relay satellite.

The typical antenna with simple conical pattern is patch antenna or across dipole antenna [5], [6]. Generally, the beam-width of this kind antenna is about $60^{\circ}$ when the gain is bigger than $2 \mathrm{dBi}$, with the study of broad beam design on this kind antenna, the antenna pattern can be broader, the beam-width of this kind antenna could be broader than $120^{\circ}$ when the gain is bigger than $2 \mathrm{dBi}$.

Fig. 1 is the measured gain pattern of a circular polarized patch antenna, the gain is bigger than $2 \mathrm{dBi}$ for the half conical angle of $60^{\circ}$.

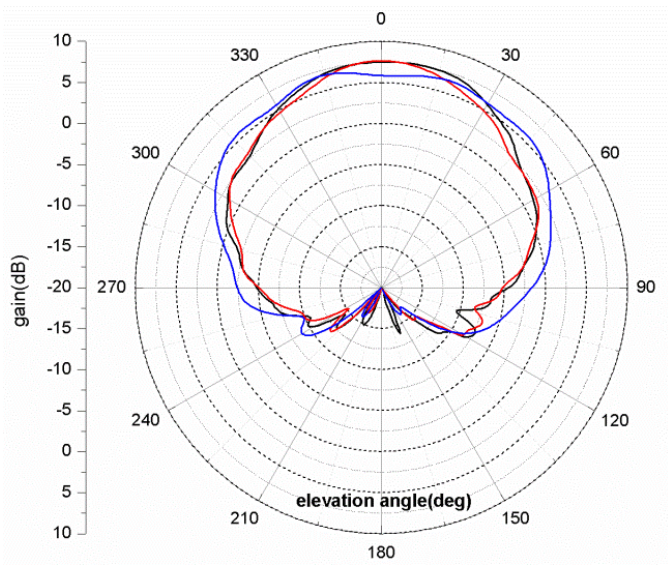

Fig. 1. Measured pattern of the patch antenna.

The typical antenna with shaped complex conical pattern is shaped helix antenna [7], [8], the inner and outer conical angle can be optimized according to the require of the project. Fig. 2 is the measured gain pattern of a shaped helix antenna, the inner and outer half conical angle for the gain bigger than $2 \mathrm{dBi}$ is $45^{\circ}$ and $80^{\circ}$ separately.

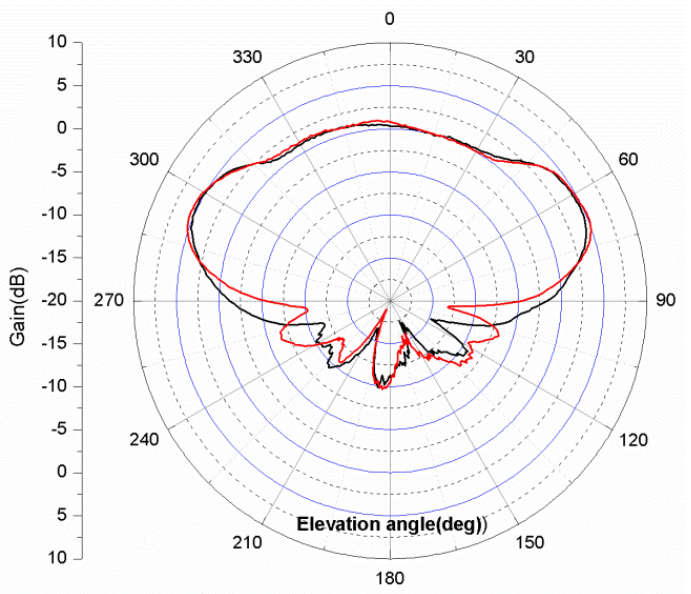

Fig. 2. Measured pattern of beam-shaped helix antenna.

Table I is the compare between the patch antenna and the shaped helix antenna with the gain bigger than $2 \mathrm{dBi}$.

TABLE I: CHARACTERISTIC OF PATCH ANTENNA AND HELIX ANTENNA WITH 2DBI GAIN

\begin{tabular}{llllll}
\hline \hline & Pattern type & $\begin{array}{l}\text { Beam } \\
\text { direction }\end{array}$ & $\begin{array}{l}\text { Beam } \\
\text { width }\end{array}$ & $\begin{array}{l}\text { Band } \\
\text { width }\end{array}$ & outlook \\
\hline $\begin{array}{l}\text { Patch } \\
\text { antenna }\end{array}$ & $\begin{array}{l}\text { Simple } \\
\text { conic }\end{array}$ & $0^{0}$ & $\geq 120^{0}$ & $\geq 10 \%$ & $\begin{array}{l}\text { Low } \\
\text { Profile }\end{array}$ \\
\hline $\begin{array}{l}\text { Helix } \\
\text { antenna }\end{array}$ & $\begin{array}{l}\text { Complex } \\
\text { conic }\end{array}$ & tunable & $\geq 70^{0}$ & $\geq 2 \%$ & $\begin{array}{l}\text { Column } \\
\text { Form }\end{array}$ \\
\hline \hline
\end{tabular}

\section{B. Access with Different Antenna Pattern}

In the following simulation, for the simple conical beam antenna, the sensor of the terminal is set as Simple Conic in STK, and the half conical angle is set as $60^{\circ}$; for the shaped complex conical beam antenna, the sensor of the terminal is set as complex Conic in STK, and the inner half conical angle is set as $45^{\circ}$, the outer half conical angle is set as $80^{\circ}$. The orbit inclination is set as $98^{\circ}$ at the same time.

Fig. 3 and Fig. 4 are the 2D access result of the terminal spacecraft with two different antenna patterns to the three relay satellites when the inclination of the terminal orbit is $98^{0}$.

Fig. 3 shows that for the simple conic beam terminal antenna the access area is focus in the round area from south latitude $60^{\circ}$ to the north latitude $60^{\circ}$. Fig. 4 shows that for the complex conic beam terminal antenna the access area is focus in the annulus area from latitude $80^{\circ}$ to the latitude $60^{\circ}$.

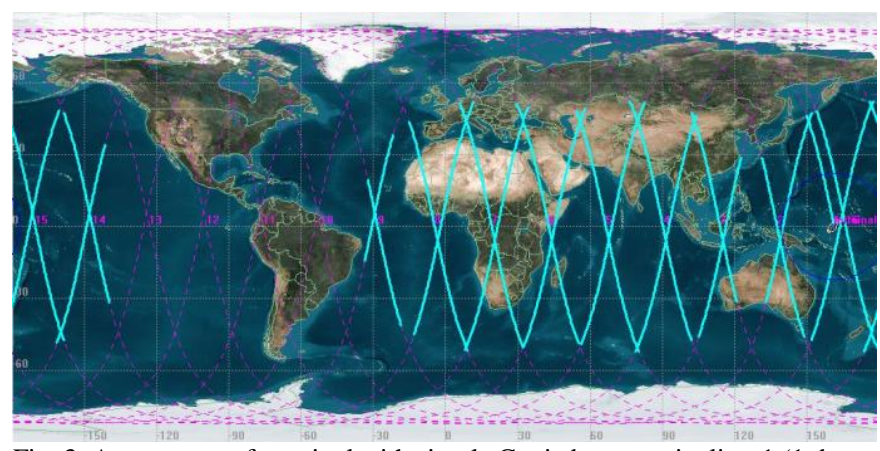

Fig. 3. Access map of terminal with simple Conic beam to tianlian-1 (1 day, orbit inclination $98^{0}$ ).

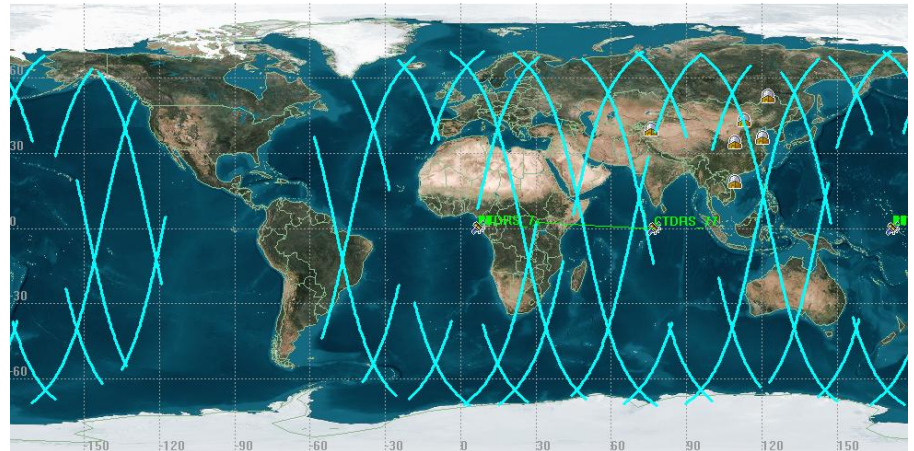

Fig. 4. Access map of terminal with complex Conic beam to Tianlian-1 (1 day, orbit inclination $98^{0}$ ).

Table II is the access data of the terminal to the three relay satellites of Tianlian-1 in one day when the pattern of the terminal antenna is simple conical and complex conical.

From the above simulation access result, when the orbit inclination is near $90^{\circ}$ for the sun synchronous orbit terminal spacecraft, the antenna with complex conical pattern will have longer access time to the relay satellite. The access area of simple conical antenna to the relay satellite is mainly focus in the round area and the center of the circle is the sub astral point; The access area of complex conical antenna to the relay satellite is mainly focus in the annulus area and the center of the circle is also the sub astral point, the annulus area expands to the two poles with the increase of the outer conical angle.

So the size of the access area is interrelated to the radiation angle of antenna pattern, when the antenna gain is same the antenna with complex conical pattern will has bigger access 
area.

TABLE II: ACCESS SUMMARY OF THE TERMINAL TO TIANLIAN-1 (THREE RELAY SATELLITES, ONE DAY)

\begin{tabular}{|c|c|c|c|c|c|}
\hline & & $\begin{array}{l}\text { Total } \\
\text { Duration } \\
{[\mathrm{min}]}\end{array}$ & $\begin{array}{c}\text { Access } \\
\text { [times] }\end{array}$ & $\begin{array}{l}\text { Max } \\
\text { Duration } \\
{[\mathrm{min}]}\end{array}$ & $\begin{array}{l}\text { Min } \\
\text { Duration } \\
{[\mathrm{min}]}\end{array}$ \\
\hline \multirow[t]{2}{*}{$\begin{array}{l}\text { Tianlian } \\
-1(01)\end{array}$} & $\begin{array}{l}\text { Simple } \\
\text { Conic }\end{array}$ & 191.1 & 8 & 26.8 & 19.7 \\
\hline & $\begin{array}{l}\text { Complex } \\
\text { conic }\end{array}$ & 281.6 & 18 & 28.6 & 8.5 \\
\hline \multirow[t]{2}{*}{$\begin{array}{l}\text { Tianlian } \\
-1(02)\end{array}$} & $\begin{array}{l}\text { Simple } \\
\text { Conic }\end{array}$ & 201.7 & 9 & 26.6 & 12.3 \\
\hline & $\begin{array}{l}\text { Complex } \\
\text { conic }\end{array}$ & 291.1 & 21 & 27.3 & 8.6 \\
\hline \multirow[t]{2}{*}{$\begin{array}{l}\text { Tianlian } \\
-1(03)\end{array}$} & $\begin{array}{l}\text { Simple } \\
\text { Conic }\end{array}$ & 200.8 & 10 & 27 & 6.7 \\
\hline & $\begin{array}{l}\text { Complex } \\
\text { conic }\end{array}$ & 276.5 & 19 & 32.4 & 7.3 \\
\hline
\end{tabular}

\section{Different Inclination of LEO Orbit}

There spread many kinds of spacecrafts in the orbit at the height around $500 \mathrm{~km}$. The characteristic of the orbit is different according to the different task of the spacecraft. In the following, the influence of the inclination of the terminal orbit on the access with the relay satellite is analyzed.

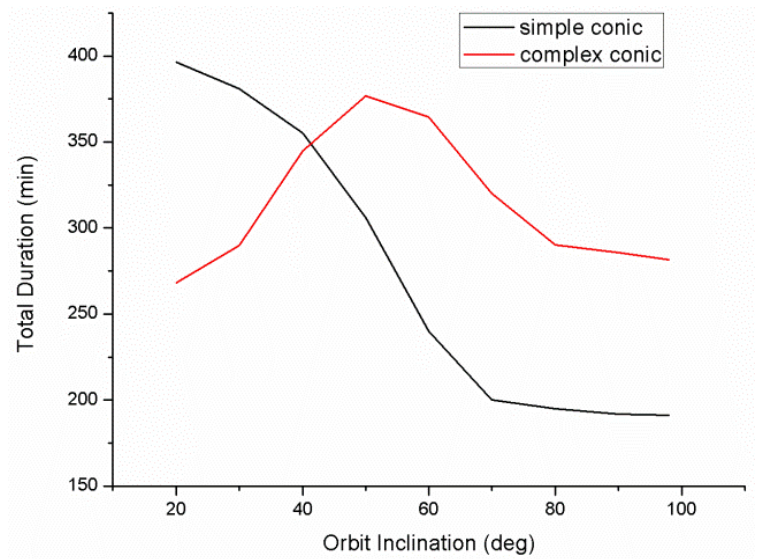

Fig. 5. Total access time of terminal with different orbit inclination to Tianlian-1(01) (1day).

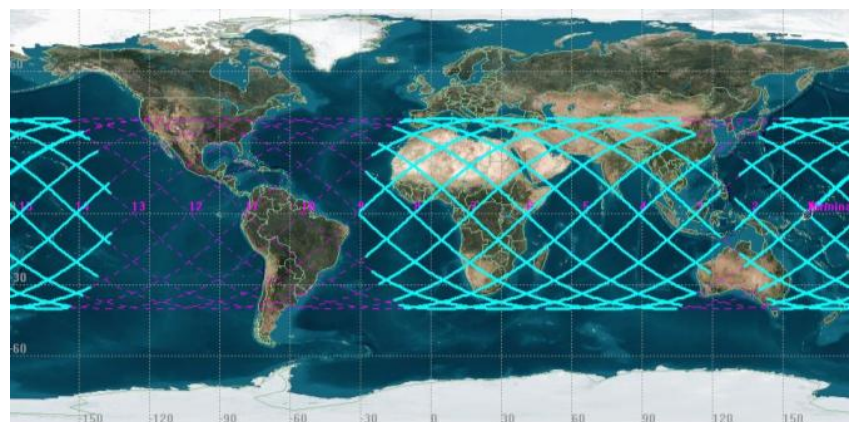

Fig. 6. Access map of terminal with simple Conic beam to tianlian-1 (1 day, orbit inclination $40^{\circ}$ ).

The total access duration of the simple conical and complex conical pattern to Tianlian-1(01) with different orbit inclination is shown in Fig. 5.

Fig. 5 shows that the access total time is longer when the orbit inclination is lower for the simple conical pattern; for the complex conical pattern, the access total time will increase with the reduce of the orbit inclination when the inclination is from $50^{\circ}$ to $90^{\circ}$, the access total time will decrease with the reduce of the orbit inclination when the inclination is from $0^{0}$ to $50^{\circ}$. So the complex conical pattern has obvious advantage on the access to the relay satellite for the higher orbit inclination, on the other way, the simple conical pattern does.

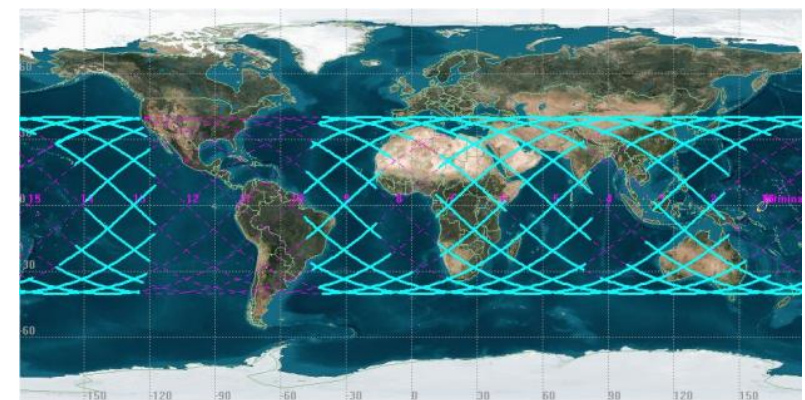

Fig. 7. Access map of terminal with complex Conic beam to Tianlian-1 (1 day, orbit inclination $40^{\circ}$ ).

Fig. 6 and Fig. 7 are the 2D access result of the terminal spacecraft with two different antenna patterns to the three relay satellites when the inclination of the terminal orbit is $40^{\circ}$. The figures show that when the orbit inclination is $40^{\circ}$, the access area is focus in the strip from the south latitude $40^{\circ}$ to the north latitude $40^{\circ}$.

The antenna with complex conical pattern has no advantage on the total access time anymore because of the less contribute of the lower elevation angle.

\section{CONCLUSION}

The relay satellite is acting as an important function in the development of space technology because of the higher coverage rate, higher data rate and the ability on multi-aim TT\&C. Minitype terminals of relay satellite act as an important role in extending the application of relay satellite. In allusion to small fixed antenna, access simulation to the relay satellite on different orbit inclination and different antenna pattern is done in this paper.

The access results of the LEO sun synchronous spacecrafts to the relay satellite indicate that for the higher inclination orbit, the antenna with shaped complex conical pattern will has better coverage performance on access; for the lower inclination orbit, the antenna with simple conical pattern will has better coverage performance on access.

The simulation result is help on optimizing the radiation power of the terminal antenna and achieving a better performance of the communication system on longer access time and lower power, it has a preferable practical perspective on the system design of minimization and lower power cost.

According to the detail requirement of the task for the terminal in the future application, more work can be done on the optimization of the gain and the beam-width of the terminal antenna.

\section{REFERENCES}

[1] N. Wang and Y.-M. Dai, "Improved TDRSS IF signal acquisition and tracking digital system," Journal of China Institute of Communications, vol. 24, no. 6, pp. 90-98, 2003.

[2] W. M. Lo, "The coverage of elliptical orbits using ergodie theory," IEEE Aerospace Conference Proceedings, vo1. 1, pp. 541-546, 2004. 
[3] D.-L. Yao, "STK and application in simulation of the communication satellite link," Science Technology and Engineering, vol. 7, no. 11, pp. 2700-2702, 2007.

[4] G.-F. Xie, "Satellite visual simulation and tracking," Control \& Automation, vol. 20, no. 9, 2004.

[5] S.-Y. Lin and K.-C. Huang, "A compact microstrip antenna for GPS and DCS application," IEEE Trans. on Antennas and Propagation, vol. 53, no. 3, pp. 1227-1229, 2005

[6] Y. Liu and X.-M. Zhang, "Design of folded-tail wide beam circularly polarized antenna," Modern Electronics Technique, vol. 32, no. 13 , pp. 50-51, 2009.

[7] X. Y. Qu and Z. Q. Yang, "A study on beam-shaping of helix antenna," Applied Mechanics and Materials, vol. 313-314, pp. 634-637, 2012.

[8] C. C. Kilgus, "Shaped-conical radiation pattern performance of the backfire quadrifilar helix," IEEE Trans, pp. 392-397, May 1975.

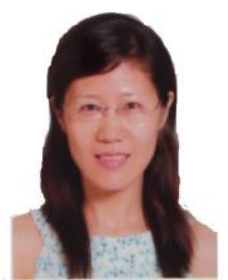

Qu Xiaoyun was born in Yantai, China, 1974. She received her master of science degree on electromagnetic field and microwave technology from the Research Institute of Nanjing Electronic Engineering in 1999, Nanjing, China. She now works for Shandong Aerospace Electro-Technology Institute as the chief designer in Yantai, Shandong Province, China. Her past project and work experience include application engineer for antenna test system and senior RF engineer on antenna design. She has more than a dozen publications in various journals and conference proceedings. Her research interest includes the study on antenna design and wireless communication.

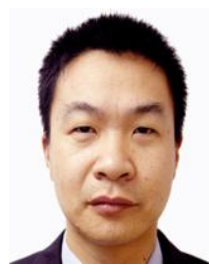

Yang Zhiqun was born in Taizhou, China, 1971. He received his $\mathrm{PhD}$ of communication and information system from Nanjing University of Science and Technology in 2004, Nanjing, China. He now works for Shandong Aerospace Electro-Technology Institute as the chief engineer on Communication in Yantai, China. His past project and work experience include software engineer on algorithm of radar and system engineer on communication. He has several patents and publication in various journals and conference proceedings. His research interest includes TT\&C system, navigation and radar.

Li Xiangyang was born in Yantai, China, 1972. He received his bachelor degree on mechanical electronic from Harbin Engineering University in 1994, Harbin, China. He works for Shandong Aerospace Electro-Technology Institute as DIRECTOR in Yantai, China. His research interest includes integrated electronic and wireless communication. 